\title{
Digital utility: Datafication, regulation, labor, and DiDi's platformization of urban transport in China
}

Julie Yujie Chen $^{\mathrm{a}^{*}}$ and Jack Linchuan Qiu ${ }^{\mathrm{b}}$

${ }^{a}$ School of Media, Communication and Sociology, University of Leicester, Leicester, U.K; ${ }^{b}$ School of Journalism and Communication, the Chinese University of Hong Kong, Hong Kong, China.

This article, develops the critical concept of digital utility through studying the case of DiDi Chuxing and the platformization of transport services in urban China. By examining DiDi's business model, its datafication strategies, its relations with the Chinese government, and its labor management systems, the platformization of transport is demonstrated to be representative of a private Internet company's transformation to a digital utility provider. With technological imagination and practical inconsistency, this process is conducted to remediate service delivery while reworking infrastructures and redefining the access to public and private services. We argue that platform companies are able to become digital utility suppliers because of their capacity to straddle the public and the private sectors, their aspiration to become "ecosystem builders," and their heavy reliance on the constant intensive labor of users, particularly drivers, to produce data. However, because of these factors, instability is a definitive feature of digital utility companies in their present condition. Morphing into the terrain of utilities is a common undertaking by DiDi and similar platform companies. To problematize the logics of digital utility, especially its labor-intensive datafication processes and its complex relations with regulators, provides a conceptual anchor for further debates on the infrastructuralization of platforms and the platformization of society.

Keywords: digital utility; ride-hailing platforms, informal economy; digital labor; algorithms

\section{Introduction}

According to official statistics, ride-hailing apps served more than 480 million Chinese in 2017 (State Information Center \& Internet Society of China, 2018, p. 30), including most of China's 793 million urban population. The predominant company is DiDi Chuxing, a private startup that was founded in Beijing in 2012, subsequently monopolizing 94.6\% of China's ride-hailing market (Xiao, 2017). By 2017, DiDi operated in more than 400 Chinese cities, where the company's 21 million registered drivers handled more than 30 million rides each day (DiDi, 2018a). This daily operational volume far surpasses Uber in the US (Crabtree, 2018); hence, DiDi is the world's leading ride-hailing platform.

When apps become the mediator of rides, they constitute an underlying digital condition for transportation services because Chinese urban dwellers depend on them for

\footnotetext{
*Corresponding author. Email: julieyj.chen@gmail.com. ORCID ID: 0000-0002-0358-0894
} 
taxi services. Analogous to electricity, these apps provide a new type of utility-a digital utility-in urban transport.

The concept of digital utility is not new. Since the early 2000s, digital utility has been discussed by critical media scholars, who have emphasized the public service functions of the Internet (Murdock, 2005; Moe, 2008; Andrejavic, 2013). The concept is also in line with proposals by computer scientists to consider computing, especially cloud computing, as the fifth utility after water, electricity, gas, and telephony (Buyya, Yeo, Venugopal, Broberg, \& Brandic, 2009). It has been long established in economics that utilities markets are prone to monopolization (Newberry, 2002), so they require state regulation to balance the interests of investors (i.e., capital) and consumers (i.e., citizens and workers) in pursuit of long-term system stability and the common good (Demsetz, 1968). The recent rise of digital platforms, such as Uber and DiDi, have made urban mobility both mundanely convenient and seemingly harmless; hence, users tend to forego their inner logic, while the lack of clear regulations hinders a systematic analysis of this phenomenon. According to van Dijck, Poell, and de Waal (2018, p. 139), "[t]he current platform ecosystem is predicated on an architecture that is primarily staked in, and driven by, economic values and corporate interests," which often endangers "public values." Therefore, it is urgent, both theoretically and practically, to critically examine the concept of digital utility and apply it to the analysis of real-world cases.

We attempt to fill the gap in the work on this phenomenon by examining the digital utility provider DiDi. The ascendency of DiDi and the platformization of transport services in China provide valuable case studies to explore what characterizes a digital utility and a digital utility supplier. The following questions guide the present study: How does an app-based platform grow into a digital utility provider? What are DiDi's datafication strategies, its complex relationships with the Chinese government as an "infrastructural state," and its labor practices, especially regarding the intensive labor performed by its driver-workers? How does DiDi resemble and differ from Uber in the platformization of transport? To what extent does our analysis of the transport sector shed light on the platformization of Chinese society?

This study is part of a two-year research project conducted from 2015 to 2017 to examine the digital platforms for on-demand services in China. The data were collected from primary and secondary materials, including official statistics on Internet users and the digital economy in China, public data, reports on DiDi, and news reports as well as official policies and regulatory documents at national and subnational levels. We collected information from DiDi's official websites in both Chinese and English, as well as research reports published or sponsored by DiDi. We conducted more than 60 interviews with DiDi drivers in several cities during the project. The argument in this paper, however, is not developed through examining the primary interview data, but by critically examining the secondary materials collected from government, corporate, and news documents. Our critical point of view, nevertheless, benefited from the driver's insights and our knowledge of their perspective.

In this article, we first discuss recent developments in the field of platform studies and develop the concept of digital utility to examine the public, private, and digital interfaces of the ride-hailing platforms. We then present our analysis of ride-hailing platforms as developing category of digital utility through the example of DiDi. The analysis is organized as follows: 1) the company's business model centered on datafication and financialization; 2) the discursive and practical strategies embodied in the company's relationships with national and local governments; 3) the obscure labor management system involved in the platformization of transport. 


\section{Platformization, Infrastructure, and Digital Utility}

Platform research has opened multiple lines of inquiry and invited trans-disciplinary theoretical discussion. Early studies revealed that politics influenced platforms and that corporate logic shaped both platforms and user experiences (Gillespie, 2010). The development of a platform involves continuous negotiations among the designers, the company, the user community, the socio-economic context and larger regulatory frameworks (Gillespie, 2010; Plantin, et al, 2018; van Dijck, et al, 2018). Apart from fulfilling the need for socialization and online expression, digital platform companies have increased in both number and type across the globe. Although their business models differ, collectively, digital platforms have surfaced as a significant force for economic configuration as well as social control (Kenney \& Zysman, 2016; Srnicek, 2016; van Dijck et al., 2018). Accordingly, scholars have shifted their research foci from technical architecture and affordances to the organizing and dominating power of platforms in the economy and the society. For example, after examining four types of platforms in news, urban transport, heath care, and education, van Dijck et al. (2018) found that "public values" must be considered in assessing the transformation to the platform society. Digital utility, as a common good that is delivered by monopolistic platforms to society, is one of the conceptual instruments used to articulate public values outside the corporate and technological spheres.

According to Plantin et al. (2018), the distinction between infrastructure and platform has become blurred in today's digital environment. On one hand, private digital tech companies fill the vacuum when governments retreat from building and maintaining universally accessible infrastructures. Such infrastructures are platformized, which implies the continuous enclosure of the open web and the lock-ins by monopolistic private gatekeepers (Zittrain, 2009). Simultaneously, giant platforms, such as Facebook and Google, have achieved a tremendous scale, reaching far beyond their core businesses. This phenomenon is known as the "infrastructuralization" of platforms.

An increasing number of studies is concerned with contextualizing digital platforms and/or their effects on life experiences. In his account of "platform capitalism," Srnicek (2016, p. 48) considered platforms "a new type of firm," the core business strategy of which was "extracting and controlling data." Previous studies that placed platform work and workers in their historical and socio-economic contexts contributed to our understanding of the ways in which established social relationships are embedded in the actual processes of crowd work and how they contribute to building solidarity among dispersed workers (Gray, Suri, Ali, \& Kulkarni, 2016). Other studies highlighted the importance of geography and the colonial legacy (e.g., certain language abilities of the residents in former colonies) for the uneven distribution of online work and the unfair competition among workers (Graham, Hjorth, \& Lehdonvirta, 2017; Irani, 2015b).

It is thus imperative to unravel the complex dynamics that shape the historical development of platforms in specific sectors. For instance, van Dijck et al. (2018, p. 73) stressed that urban transport "is largely a market sector, but it has a considerable public interest," focusing on "two central public values: the quality of urban transport and the organization of labor and workers' rights." Van Dijck et al. understood "quality" as not only the narrow consumer viewpoint of using transportation services with efficiency and comfort but also "consumer protection, passenger safety, inclusiveness [...], universal service provision [...], and affordability" (2018). Articulated in European contexts, this wide conceptualization sheds light on our interrogation of DiDi's digital utility in Chinese cities.

Two questions remain unaddressed in the field of platform studies. First, the dual process of "platform-as-infrastructure, and vice versa" (Plantin et al., 2018, pp. 306-07) 
deserves more rigorous scholarly interrogation, particularly regarding the reasons why certain platforms become infrastructure while others do not. What developmental course does "platform-as-infrastructure" take in specific national contexts? Second, the "extractivism" nature of platform capitalism has been widely acknowledged (Scholz, 2016; Srnicek, 2016), but little analysis has been conducted regarding how companies leverage their financial, technological, and discursive strategies, among others, to accomplish data extraction.

We develop the concept of digital utility to critically evaluate the characteristics of "platform-as-infrastructure." We define digital utility as (a) public services and values, which was proposed by Murdock (2005), Moe (2008), Andrejevic (2013), and van Dijck et al (2018) and (b) transformed digital conditions embedded in the access to public or private services, without which the utilization of such services would be categorically different (Plantin et al., 2018). Thus, digital utility may be understood to be a subset of the services delivered by platform infrastructures the public value of which is discounted, thereby requiring increased state regulation. The data-driven nature of the platform economy (Srnicek, 2016) determines the transmutation to digital utility in the constant flux of data capture. Therefore, digital utility is intertwined with data production and manipulation in users' access to and utilization of the services mediated by infrastructural platforms.

The creation and supply of digital utility distinguishes infrastructural platforms from non-infrastructural platforms. Google is a digital utility platform for the following reasons: 1) it transforms the digital conditions for Internet users to navigate and utilize the web; 2) it expands to several other domains, including maps and books (Plantin et al., 2018); 3) Google's service could not be accomplished without its streamlined data collection and manipulation mechanism. In China, ride-hailing apps can also be assessed as digital utility platforms because without them, it would be substantially difficult to obtain a taxi service nowadays. These apps have also overlain the urban infrastructure of roads and traffic, catalyzing the datafied transport system. In contrast, Airbnb currently falls short of being a digital utility supplier because although it arguably has changed the short-term rental market, it has not yet been linked to other infrastructures to the extent that it would fundamentally affect tourists' access to accommodation.

Digital utility simultaneously constitutes and alters the terms of access to public and private services. Not all interactions on platforms take place on equal settings or generate identical outcomes. On the contrary, "data-based discrimination" (Gangadharan, 2014, p. 2) or "selection" (van Dijck et al., 2018, p. 40) is the new norm, which is particularly the case in labor platforms, which systematically reinforces the economic disadvantages of marginalized workers (Chen, 2017; van Doorn, 2017). Workers and consumers install different versions of the same app, wherein the former face far more intensive data extraction and surveillance, such as the rating system, tracking, and feedback, than their client counterparts do (Irani, 2015b; Rosenblat \& Stark, 2016). Consequently, on these platforms, the unequal access determined by digital platforms and automated by algorithms has the dual function of turning participant workers into datafication workers.

The distinction between digital utility and traditional utilities, such as electricity, is crucial: the source of power for digital platforms - datafication-depends not only on algorithms, technology, and non-human natural resources but also, more crucially and intensively, on humans themselves. Although it could be argued that telephony also draws on human resources, such as caller networks, in providing a utility service, the data extraction from human supplementers on today's platform infrastructures, which we call "digital utility labor," is qualitatively different in economic value and cybernetic control. 
Labor relations scholar Xiaoyi Wen contended, "the real nature of the sharing economy is the labor-intensive economy” (2018).

\section{Platformization of Transport and the Rise of a Digital Utility Supplier}

The rise of DiDi as China's ride-hailing platform monopoly demonstrates universal patterns of datafication and the intensive extraction of labor from supplementers. However, the specific case of China and its historical context are equally important in developing the concept of digital utility.

First, China is a socialist country that is governed as an "infrastructural state" (Bach, 2016). Without the direct investment by government in its infrastructure, DiDi became an unparalleled behemoth with a $94.6 \%$ share of the ride-hailing market (Xiao, 2017). Beginning in the 1980s, taxi services in China were part of the urban public transport systems. However, in 2016, the Measures for Administration of Urban Taxi Business Operations and Services defined the taxi service as a "supplement" to public transport, which means that the business can be privately owned or operated, but it must serve the public interest. Ride-hailing platforms such as DiDi offer both traditional taxi services and private car services. Hence, DiDi insists on its self-branding as a "one-stop" transportation platform, differing from Uber, which claims to be a "connective platform" in Europe (van Dijck et al, 2018, p. 73). In China, the state regulation of ride-haling apps met little opposition because of the sectoral history of taxi services. This history has led China to become one of the first nations to legalize and regulate ride-hailing apps.

An equally important legacy is that China has never had a nationally centralized taxi management system. Instead, each city has rules and regulatory structures, thereby forming a "multi-headed, multi-tiered management" system (Chen, 2017, p. 7) that continues to characterize DiDi's business today. Wealthy local governments on the east coast, such as in Shanghai, tend to take more responsibility, sometimes directly owning or subsidizing taxi businesses, than less developed cities in the hinterlands, which follow a hands-off approach or prey on taxi drivers and companies through exploitative rentseeking.

A common grievance among drivers concerns the ways in which local governments treat unlicensed vehicles, which are known as "black cars" (heiche) persisting from taxi industry to the ride-hailing market. Ride-hailing apps, including DiDi, transformed urban transport in China after it overtook the US in becoming the world's largest car market (Bragnigan, 2012). From 2000 to 2012, private car sales in China soared from 4 million to about 18 million. The ride-hailing market expanded phenomenally within a few years. In 2017, 278 million people used apps for traditional taxi services. and 217 million people used apps to hire a private car (CNNIC, 2017, p. 26). On the DiDi platform, 30 million rides are delivered every day (DiDi, 2018a). DiDi had 450 million users and 21 million registered drivers by the end of 2017, surpassing Uber's performance worldwide (Crabtree, 2018; DiDi Institute of Policy Study, 2017). In DiDi's report, however, the company did not clarify the number of legally licensed vehicles or the number of "black cars."

\section{Datafication, financialization, and "DiDi Traffic"}

Similar to its western counterparts, DiDi's business strategy involves multiple integrated operations that help achieve the company's monopoly, maintain its competitive advantage, and reshape the terms of access to private transport service. At the core of all operations are datafication and financialization.

Founded in the post-2009 context of quantitative easing, which has provided structural backing and penetration by the financial sector globally, DiDi combines 
financialization to pursue market shares with the construction of its data capture infrastructures. Jia and Winseck (2018) showed that the leading Chinese Internet companies, Tencent, Alibaba, and Baidu, resemble global giants like Apple in their integration into the financial market as investors and recipients of transnational capital. DiDi is similarly financialized in global capital flows. Among the top investors in DiDi are the tech companies Apple, Alibaba, Booking, Softbank, and Tencent (Crunchbase, 2018). In addition to private funds, DiDi attracts investment from state-owned enterprises such as China Life Insurance, which is the largest life insurer in China, and the China Investment Corporation, which is a sovereign wealth fund that manages China's foreign exchange reserves.

Internet companies also buy out other companies to make inroads into unfamiliar markets and increase their competitiveness (Jia \& Winseck, 2018). Mergers and acquisitions are typical financialization maneuvers to achieve this end. DiDi's merger with Kuaidi in 2015 and its subsequent purchase of Uber China in 2016 helped establish its monopoly in China. Globally, DiDi launched Kuaidi Taxi in Hong Kong, acquired 99, Brazil's largest rideshare company, and invested in or established strategic partnerships with transport platforms for both traditional taxis and private hires in Europe, Africa, Middle East, Southeast and South Asia, and North Africa (DiDi, 2018b).

What sets mergers and acquisitions by platform companies apart is their special concern with data - the essential assets in financialization measures, because they enable platform companies to possess colossal amounts of data on users and habituated data capture infrastructures. Data underlie DiDi's platform operation and its expansion to a wide range of urban transport from taxi services to diverse private car services to the recent bike-sharing and smart-traffic systems. In 2018, DiDi handled 30 million ride requests daily, which generated 106 terabytes of data per day. Consequently, DiDi processed more than 4,875 terabytes of data daily ( $\mathrm{DiDi}$, 2018a), which were collected to train DiDi's algorithms, ranging from pricing and job-allocation to predicting and mitigating traffic congestion and developing “a safe driving system” (Xiao, 2017).

However, unlike patterns in western countries, DiDi has not disrupted the taxi industry by replacing taxi drivers by private gig drivers, which is based on corporate discursive and political strategies at various levels of the Chinese government. DiDi has established partnerships with more than 50 leading taxi companies in Tier- 1 and Tier-2 Chinese cities. Moreover, it has aimed to datafy the urban transport ecosystem, including taxis, and occupy the center of the converging networks of information, traffic, and transactions involving all kinds of vehicles and transport services. The company calls this converging datafied system "DiDi Traffic," which is in operation in more than 50 cities. The scheme integrates data captured by DiDi with data sources from local government and related business partners to manage city traffic.

DiDi Traffic is far more than "a traffic information platform" that offers local transportation authorities real-time traffic information (DiDi Chuxing Development Research Institute, 2017, p. 36). It has enabled DiDi to become a central component in the datafied urban transport infrastructure. Data and data capture mechanisms have allowed DiDi to shape the digital conditions for urban transport. Hence, DiDi enters the terrain of supplying digital utility in urban transport.

\section{Political strategy: Align with the central but wrestle with the local}

According to Srnicek (2016, p. 92), "far from being owners of information, these [platform] companies are becoming owners of the infrastructures of the society [emphasis added]." Infrastructure, however, is always embedded in "other structures, social arrangements and technologies” (Star \& Ruhleder, 1996, p. 113). Infrastructural 
construction is as material as it is affective because it involves the imagination of infrastructure as the pathway toward a modern, more advanced, and better future (Larkin, 2013). DiDi's rapid expansion and platformization of transport services in China, therefore, must be examined against the backdrop of China as a prominent "infrastructural state” (Bach, 2016) and the company's infrastructural encounters at the local level. DiDi's political strategy is characterized by 1) its alignment with the development and technocratic rhetoric of the Central Government and 2) its contestation of local authorities, which has had mixed outcomes. The interplay among the technocratic rhetoric adopted by the platform company, the local state regulations, and existing informal practices has exacerbated the complexity and contradiction of the governance of transport platforms and digital utility.

China is an "infrastructural state" that channels $43 \%$ of its total investment in infrastructure (Bach, 2016) from building networks of road and railways to constructing urban skyscrapers. Recently, the authorities not only have invested heavily in upgrading telecommunication infrastructures but also have appropriated Internet and related technologies (e.g., automation and AI) into a discourse of techno-panacea on modernization, economic restructuring, and social development (Hong, 2017). DiDi has aligned with this technocratic narrative by positioning itself as the technological solution provider to problems such as structural under- or unemployment and traffic congestion. In so doing, the company has enlisted itself to become part of the driving force to materialize the nation state's imagination and its desire to become a global ICT leader through an "infrastructural fix" (Bach, 2016).

Different from the "cultural work" done by crowdwork platforms to dehumanize and invisiblize workers, DiDi's job-creation rhetoric does the "cultural work" (Irani, 2015b) of sublimating the platform's pursuit of its private interest in a discourse of social service provision and contribution to the national strategy for economic restructuring. In addition to promoting the number of jobs created by the platform, DiDi tends to highlight how flexibility in "gig driving" work helps mitigate the infliction of an economic slowdown on ordinary workers. For example, in 2016, DiDi claimed to have created 17 million flexible jobs, stressing that 2.4 million jobs were held by workers in heavyindustry sectors that had been affected by national initiatives to reduce excessive industrial capacity. DiDi's job-creation figures were cited in an official report on China's sharing economy (State Information Center \& Internet Society of China, 2017). Another report on DiDi's gig drivers in 2017 stated that more than 21 million drivers had earned part or all of their income from DiDi, and the number of drivers from the capacity-cutting sectors had climbed to 3.9 million (DiDi Institute of Policy Study, 2017). The emerging gig driving work is promoted by both the company and governmental agencies as a benign solution to absorb millions of newly laid-off factory workers or underemployed workers. However, empirical studies have shown contradictory evidence that new gig drivers are concentrated in and are more likely to come from economically better-off coastal regions that places affected by capacity-cutting policies (DiDi Institute of Policy Study, 2017).

DiDi also has attempted to broker its infrastructural imagination of a datafied transportation system to local cities. DiDi Traffic is an example. Although cities allegedly have taken advantage of the talent on DiDi's engineering team, the platform company has benefited considerably from data-sharing and consolidation with local authorities because this partnership enables DiDi to design and be part of the emergent digital transmutation of the urban traffic and transport system. Moreover, it allows DiDi to further straddle the line between private and public services. No specific law or policy exists to regulate the sharing and/or commodification of data except the general provision in China Cybersecurity Law to protect individual's private data. Because of this regulatory vacuum 
and DiDi's dual position, the company benefits from what legal scholar Victor Fleischer called "regulatory arbitrage” (cited in Calo \& Rosenblat, 2017, p. 1627).

When a platform that is designed to harness data at scale sinks in and intersects with local infrastructure and power relationships, incongruities surface. In contrast to its high-profile market expansion, DiDi and its drivers remain in a legal "gray zone." As of June 2018, DiDi has obtained legal operational licenses in only 51 cities in China while it operated in over 400 cities (Yue, 2018), and legitimate platform drivers for DiDi accounted for only $0.6 \%$ of the entire workforce (China News, 2017). Most DiDi drivers in effect earn money outside regulations or formal institutions. They are unlicensed platform drivers similar to the "black car" drivers in the days prior to platformization.

Previous studies showed that digital platforms may formalize and standardize previously informal service sectors (Ticona \& Mateescu, 2018). DiDi has formalized transport services to some extent. By standardizing algorithms that function as labor control mechanisms disciplining worker-drivers (Rosenblat \& Stark, 2016), the platform consolidates DiDi's control and brings several informal practices to the verge of regulation. Private fare negotiations and cash transactions have been replaced by pricing algorithms and money transfers through integrated third-party payment apps, such as WeChat Pay and Alipay. Transaction data on both ride-hailing platforms and third-party payment apps are traceable.

After the national legalization of ride-hailing platforms in 2016, more than two thirds of Chinese cities passed and enacted local regulations with varying restrictions on platform drivers and vehicles (Ma \& $\mathrm{Li}, 2017)$. These restrictions are focused on qualifications for platform drivers and requirements for vehicles. Three quarters of the city governments in China, however, have imposed local residency mandates on drivers (Ma \& Li, 2017). Although migrant workers account for the majority of DiDi drivers, these local regulations preclude them from this employment. Legal barriers of this kind have reduced the number of legitimate platform drivers, which reflects the local resistance against platformization and the acceptance of the digital utility provided by DiDi. For instance, several cities in Jiangsu Province issued fines for DiDi's lack of legal operational licenses in its jurisdiction as well as the illegal recruitment of unqualified drivers to work on the platform (Yangtze Evening Paper, 2017).

In practice, DiDi not only acquiesces in the participation of "black car" drivers to work on its platform (Chen, 2017) but also breaches local regulations brazenly. In addition to the fines imposed on DiDi, local authorities prohibited unlicensed platform drivers in the same manner as they used to repress "black cars" in taxi industry. Hence, the legacy of "multi-headed, multi-tiered management" characterizing the taxi industry has been extended and exacerbated. Local frictions have caused informal practices to persist during and after platformization, which has benefited DiDi, which continues to exploit the precarious economic position of its drivers.

The contradiction between the efforts at formalization by national and local regulatory bodies, the ride-hailing apps, and the preservation of informal or even illegitimate practices describes the positions of both DiDi and its drivers. The incongruities inherent in the ride-hailing platform have allowed its development into a digital utility, through which DiDi aspires to both scalability and applicability in local settings. The scalability of tech companies is achieved by reducing workers to "computational power" (Irani, 2015a), whereas the applicability to local settings demands the agility of drivers who remain in an informal state, whether it is voluntary or not. DiDi's complicity in the selective formalization of its ride service is not coincidental but deliberate. 


\section{Platformization and Digital Utility Labor}

What is the relationship between the digital utility provider DiDi and its labor force? In this section, we explains how DiDi's platformization of transport precipitated a profound shift in platform labor relations toward discriminatory data extraction. This shift, we argue, lays bare the centrality of digital utility labor, which means that DiDi's drivers not only transport people but also feed data into the system to train algorithms and sustain the platform's operations and infrastructure. Datafied digital utility labor, consequently, is a distinct feature of today's platform infrastructures, which was not observed in traditional utility markets.

In May 2015, the CEO of DiDi, Cheng Wei, announced his Great Tidal Strategy, or "Tides" (Guo, 2015). In the following three years, Cheng discussed his vision on multiple occasions, including his keynote speech at China's Big Data Industry Summit in 2016 (People.cn, 2016), and expanded it from a strategy to "integrate professional transport ability with socially scattered transport ability to satisfy people's transportation demand in the peak and off peak hours" (Guo, 2015) to a strategy for collaborating with local governments to solve traffic jams and build a "smart city" (DiDi Chuxing Development Research Institute, 2017). Since 2015, DiDi has dominated China's online transport services by offering a full range of on-demand mobility options, including taxis, private car hailing, ride-sharing, chauffeurs (i.e., designated drivers), business limousines, minibuses, and car rentals. "Tides" was introduced in addition to the surgepricing algorithm as a tool for managing and controlling the supply side of transport services. Surge pricing, which incentivizes drivers by cash rewards, can be self-defeating because they could generate an influx of service providers and then reduce the incentives.

However, "Tides" is more than an algorithm; it is a system that rations, dispatches, and routes all vehicles that are available on the platform to accommodate transport demands based on the optimal calculations of real-time data (Crouch, 2016). Instead of reacting to the outbreak of an imbalanced supply-demand market, "Tides" is deployed to map the distances and destinations of all requested rides and to strategize the routes for each driver to travel, thus precluding a surge price. DiDi aims to "predict traffic hotspots in advance" and "outsmart traffic" through data analytics (Crouch, 2016). "Tides" is a grand plan for restructuring urban transport, which depends on an enormous amount of data. If it were in full swing, it would not only help "mitigate traffic jams," but orchestrate and control local traffic. It would become the protocol for digital transport infrastructure, expanding Galloway's (2001) idea of protocol as the control mechanism for decentralized networks. "Tides" is in effect a cybernetic strategy for the control of platform labor.

Studies on labor platform have documented the constitutive role played by algorithms in labor management for quality control, labor performance monitoring and surveillance, and labor valorizations (Chen, 2017; Rosenblat \& Stark, 2016). The cybernetic labor control mechanism of "Tides" is concerned with both labor discipline and data capture. It extracts data through digital utility labor and disciplines drivers through feeding data into algorithms. As such, "Tides" creates a two-tiered access and data extraction wherein the drivers produce far more data than the passengers do, which makes platformization of transport services in China essentially a "labor-intensive economy" of datafication.

According to Etherington (2016), DiDi collects information about drivers' locations and speed every three seconds. In a newly developed "safe driving system," a dashboard camera captures everything from road conditions, following distances, and reckless driving to potential signs of fatigue (Xiao, 2017). Through sensors on phones, DiDi gathers data on drivers' patterns of accelerating, braking, and steering (Crabtree, 
2018). The trip and service histories of drivers are tracked and categorized by algorithms to predict whether an individual driver has the propensity to inflate passenger fares by taking overly long routes. When these drivers are detected, “Tides" places these drivers on a dispatch list of drivers that are eligible for only short-distance trip (e.g., within three miles).

"Tides" epitomizes what Zuboff described as the "big other": operations of "unexpected and often illegible mechanisms of extraction and control that exile persons from their own behavior" (2015, p. 85). Zuboff (2015) and others (e.g., Fuchs, 2010; Turow \& Couldry, 2018) acknowledged that all participants in the "big other" are subject to data extraction, and in the case of DiDi, data are extracted from both drivers and passengers. Drivers carry out a double task by offering a transport service and generating data, which constitutes the digital utility labor. The intensification of data capture by drivers could be interpreted as the multiplication of labor in the work process as a means of generating value to "secure and obscure surplus labor" (Burawoy, 1979, p. 81) from drivers for datafication.

The uneven work of data production that pervades labor platforms is justified by the reasoning that workers need to be controlled and disciplined. A crucial condition for systems such as "Tides" is to have drivers follow instructions given by algorithms, such as a suggested route. Therefore, the driver must accept the allocated order, instead of going home. Thus, discriminatory data production has become the default foundation of DiDi and digital utility platforms. Because of the structural precariousness of the migrant workers and laid-off workers who comprise the majority of DiDi drivers, these informal drivers are easy prey in DiDi's business model, which was first designed to attract taxi drivers and then was expanded to other transport markets (Chen, 2017). DiDi has become a surveillance-based data extraction company that has enjoyed China's current lax data protection laws in its ascendance to a market monopoly. Hence, based on the case study of DiDi, digital utility labor is both a distinct resource and an inherently vulnerable component of digital utility platforms.

\section{Discussion}

The case of DiDi raises new questions in the current approach to the Chinese digital economy, which has tended to be top-down in investigations of the power relationships among capital, private enterprises, and the state (e.g., Hong, 2017; Jia \& Winseck, 2018; Zhao, 2007). No more "dancing” with foreign "wolves," at least in the digital platformbased transport sector, domestic companies, such as DiDi, have become the "wolf" that devours foreign apps, market shares, workers' labor, and most importantly, the data generated by all parties involved. Our study has examined the historical dimensions of a platform growing into a digital utility company, thereby transforming the relations between drivers and the platform as well as between the platform and governments at various levels. Based on our analysis, the following can be said about the platformization of ride services in China and about our contribution to the current debate about the platform society through the conception of digital utility as both an empirical process of pervasive service delivery and a normative construction of infrastructural platforms.

Based on our analysis of DiDi, platformization includes two processes, both of which are essential to the provision of digital utilities: 1) the digital mediation of transport services, including the driving process; 2) the reworking of digital and social infrastructures for urban transport through the datafication of the first process. A dozen ride-hailing apps, including DiDi, have contributed to the first process. DiDi's rise to a monopoly set the second process in motion. The case study of DiDi complicates the discourse of innovation, which is often deemed oppositional and "disruptive" of existing 
models. Undoubtedly, DiDi has transformed habitual ride services in urban China by becoming an indispensable digital utility provider. Nevertheless, the company is reluctant to disrupt the existing structures of the taxi industry because it benefits immensely from its exploitation of informal labor, which it continues to employ in the datafication of its transport system. Our analyses about the platformization of urban transport thus offer a glimpse into the platformization of Chinese society in general. DiDi's datafication practices and its infrastructural imagination are shared with the government.

Despite its strategies and its rhetoric of standardization to create a better, modern transport system, DiDi has not, and probably will not, eradicate its informal practices in the new digital utility system, particularly its reliance on informal worker-drivers. It is therefore very likely that the relationship between $\mathrm{DiDi}$ and Chinese authorities, especially local state governments, will never be as fully formalized as the traditional utility sectors have been. The new digital utility firms sometimes may outsmart the authorities by using datafication power and algorithms. At other times, local states, which need to collect taxes to maintain roads and bridges while facing the consequences of unemployment and inadequate urban transport may resist the transmutation into digital utilities.

Building on Murdock (2005), Moe (2008), Andrejevic (2013) and van Dijck et al. (2018), we developed the concept of digital utility to investigate the profound changes brought about by DiDi and platformization as well as their consequences for the articulation of public values and the enhancement of the public welfare. Our conceptualization of digital utility is based on the socio-techno transformation and the engineered differential access and hence on the different experiences of privately owned platforms that have become essential in public life. Nonetheless, DiDi is only one marketbased model of the platformization of society. Other models are possible that could be either state-led or government-owned or based on platform co-ops and similar civil society initiatives (van Dijck et al., 2018).

The concept of digital utility captures characteristics of platform infrastructure that have yet to be fully articulated. It shifts scholarly attention away from the technicality of platforms to the outcomes they generate for the larger socio-economic system and for the public interest. In particular, our analysis of DiDi's datafication strategies has determined the constitutive features of digital utility, particularly those that enable certain platforms to become an infrastructure, which has laid the groundwork for future scholars to investigate the "hidden work" and "invisible workers" (Crain et al., 2016) in app-based service delivery. This last point is applicable beyond the platformization of transport in China. For example, the questions of who creates digital utility and under what conditions should be among the first to be addressed in examinations of a new platform infrastructure in China or elsewhere.

Because they resemble traditional utilities, digital utility companies should be obligated to serve the public interest. However, in reality, they often act on self-interest and ignore workers' rights; therefore, digital utility labor is a distinct source of systemic volatility. This revelation has wider analytical applicability to the contemporary debate on digital platforms and governance, which transcends the contexts of China and its ridehailing sector. Digital utility platforms are characterized by algorithmic flexibility and reliance on platform workers to produce data, which creates the potential for labor resistance. Hence, there is another key question for future research: Does digital utility labor render the platform infrastructure more fragile than traditional infrastructure systems do? Moreover, it is important to note that a digital utility is not independent of traditional utilities. Instead, it extends from and repurposes existing utilities. Thus, the 
knowledge about traditional utility infrastructures and their historical transmutations may lead to innovative analyses of digital utilities and the future of platformization.

\section{Conclusion}

This article is among the first to report the development of the concept of digital utility in a case study of DiDi, including its corporate history, datafication models, relationship with Chinese authorities, and labor management system. Our findings showed three empirical features that characterized the current digital utility platform: 1) DiDi's capacity to straddle formal and informal economies at the margins of government regulation, especially in relation to local state regulators; 2) its capacity to be an "ecosystem-builder" through financialization, datafication, and infrastructural projects, such as DiDi Traffic; 3) its constant and intensive data extraction practices, which are made possible by the exploitation of digital utility labor. These are the three primary reasons that DiDi has become a digital utility provider of urban transport in China. While the first reason is probably specific to the Chinese context because of the unique development of the taxi industry in urban China, the second and third features are globally relevant.

In addition to guiding the empirical analysis of datafication, the corporategovernment relationship, and labor management systems, the concept of digital utility led us to critically evaluate the platforms' public values along the lines suggested by van Dijck et al. (2018). Consequently, digital utilities should be widely accessible and affordable; they should be regulated at different levels of government; they should adhere to international and local labor standards. Labor, including digital utility labor, is the foundation and lifeblood of the sustainability of digital utility. Utilities must be sustainable; otherwise, they risk becoming the worst urban hazard.

\section{Acknowledgments}

The authors would like to thank the anonymous reviewers and the editors of the special issue-Jeroen de Kloet, Thomas Poell, and Guohua Zeng-for their valuable comments on the manuscript.

\section{Funding}

Funding for this study was obtained from the Seed Money for Project on Digital Labor, which is supported by the Faculty of Social Science at the Chinese University of Hong Kong, Hong Kong SAR, and International Development Research Centre (project \#108339-007: Deliver on the promise of the platform economy in China).

\section{Notes on contributors}

Julie Yujie Chen is a lecturer in the School of Media, Communication, and Sociology at the University of Leicester. Chen studies how cultural difference, technologies, and existing economic structure affect the experience and perception of work in the digital age. Her previous work has been published in New Media \& Society among other journals, and she is the lead author of Super-sticky WeChat and Chinese Society (2018).

Jack Linchuan Qiu is a professor at the School of Journalism and Communication at the Chinese University of Hong Kong. He is the author of Working-class network society: Communication technology and the information have-less in urban China (2009) and Goodbye iSlave: A Manifesto for Digital Abolition (2016). 


\section{References}

Andrejevic, M. (2013). Public service media utilities. Media International Australia, 146, $123-132$.

Bach, J. (2016, August 30). China's infrastructural fix. Retrieved from https://limn.it/articles/chinas-infrastructural-fix/

Branigan, T. (2012, December 14). China and cars: A love story. The Guardian. Retrieved from http://www.theguardian.com/world/2012/dec/14/china-worldsbiggest-new-car-market

Burawoy, M. (1979). Manufacturing consent. Chicago, IL: University of Chicago Press.

Buyya, R., Yeo, C. S., Venugopal, S., Broberg, J., \& Brandic, I. (2009). Cloud computing and emerging IT platforms: Vision, hype, and reality for delivering computing as the 5th utility. Future Generation Computer Systems, 25(6), 599-616. Retrieved from https://doi.org/10.1016/j.future.2008.12.001

Calo, R., \& Rosenblat, A. (2017). The taking economy: Uber, information, and power. Columbia Law Review, 117(6), 1623-1690.

Chen, J. Y. (2017). Thrown under the bus and outrunning it! New Media \& Society, 121. Retrieved from https://doi.org/10.1177/1461444817729149

CNNIC (China Internet Network Information Center). (2017). 40th statistical report on internet development in China. Beijing, China. Retrieved from https://bit.ly/2SlJ5Ic (in Chinese)

Crabtree, J. (2018, April). DiDi Chuxing took on Uber and won. Now it's taking on the world. WIRED UK. Retrieved from https://bit.ly/2EW2t8M

Crain M.G., Poster, W., \& Cherry, M. A. (Eds.) (2016). Invisible labor: Hidden work in the contemporary world. Oakland, California: University of California Press.

Crouch, E. (2016, May 27). China's DiDi wants to make traffic jams a thing of the past. Retrieved from https://bit.ly/1Rwz2ak

Crunchbase. (2018, July). DiDi Chuxing funding rounds. Retrieved from https://bit.ly/2QO0Lzt

Dai, X. (2002). Towards a digital economy with Chinese characteristics? New Media \& Society, 4(2), 141-162.Retrieved from https://doi.org/10.1177/14614440222226316

Demsetz, H. (1968). Why regulate utilities? The Journal of Law \& Economics, 11(1), 5565.

DiDi. (2016). Job creation - VALUES - DiDichuxing.en. Retrieved from http://www.DiDichuxing.com/en/values/job-creation

DiDi. (2018a). DiDi brain. Retrieved from https://www.DiDiglobal.com/science/brain (in Chinese)

DiDi. (2018b, April). Milestone. Retrieved from https://www.DiDiglobal.com/aboutspecial/milestone (in Chinese)

DiDi Chuxing Development Research Institute. (2017). New economy new service. Beijing, China: DiDi Chuxing Development Research Institute. (in Chinese)

DiDi Institute of Policy Study. (2017). New economy, new jobs. Beijing, China: DiDi Institute of Policy Study. (in Chinese)

Etherington, D. (2016, December 2). DiDi’s CTO explains why China's ride-sharing giant has a data advantage. Retrieved from https://tcrn.ch/2CyIKwt

Fuchs, C. (2010). Labor in informational capitalism on the Internet. The Information Society, 26, 179-196. 
Galloway, A. (2001). Protocol, or, how control exists after decentralization. Rethinking Marxism, 13(3), 81-88.

Gangadharan, S. P. (2014). Data and discrimination. Washington, DC: New America. Retrieved from https://bit.ly/2LD0oSI

Gillespie, T. (2010). The politics of “platforms.” New Media \& Society, 12(3), 347-364. Retrieved from https://doi.org/10.1177/1461444809342738

Graham, M., Hjorth, I., \& Lehdonvirta, V. (2017). Digital labor and development. Transfer: European Review of Labour and Research, 23(2), 135-162. Retrieved from https://doi.org/10.1177/1024258916687250

Gray, M. L., Suri, S., Ali, S. S., \& Kulkarni, D. (2016). The crowd is a collaborative network. In CSCW'16 Proceedings of the 19th ACM (pp. 134-147). ACM Press. Retrieved from https://doi.org/10.1145/2818048.2819942

Guo, G. (2015, May 22). DiDi Kuaidi releases tides strategy. Retrieved from https://www.iyiou.com/p/17838.html (in Chinese).

Hong, Y. (2017). Networking China. Urbana, IL: University of Illinois Press.

Irani, L. (2015a). Difference and dependence among digital workers. South Atlantic Quarterly, 114(1), 225-234. Retrieved from https://doi.org/10.1215/003828762831665

Irani, L. (2015b). The cultural work of microwork. New Media \& Society, 17(5), 720739. Retrieved from https://doi.org/10.1177/1461444813511926

Jia, L., \& Winseck, D. (2018). The political economy of Chinese internet companies: Financialization, concentration, and capitalization. International Communication Gazette, $\quad 80(1)$, 30-59. $\quad$ Retrieved from https://doi.org/10.1177/1748048517742783

Kenney, M., \& Zysman, J. (2016, Spring). The rise of the platform economy. Issues in Science and Technology, 32(3). Retrieved from http://issues.org/32-3/the-rise-ofthe-platform-economy/

Larkin, B. (2013). The politics and poetics of infrastructure. Annual Review of Anthropology, 42(1), 327-343.

Ma, L., \& Li, Y. (2017, November 28). China's ride-hailing platform policies review and suggestions. $\quad$ Retrieved from http://www.thepaper.cn/newsDetail_forward_1882926 (in Chinese)

Moe, H. (2008). Dissemination and dialogue in the public sphere. Media, Culture \& Society, 30, 319-336.

Murdock, G. (2005). Building the digital commons. In G.F. Lowe \& P. Jauert (Eds.), Cultural dilemmas in public service broadcasting (pp. 213-231). Goteborg, Sweden: Nordicom.

Newberry, D. M. (2002). Privatization, restructuring, and regulation of network utilities. Cambridge, MA: MIT Press.

Plantin, J.-C., Lagoze, C., Edwards, P. N., \& Sandvig, C. (2018). Infrastructure studies meet platform studies in the age of Google and Facebook. New Media \& Society, 20(1), 293-310. Retrieved from https://doi.org/10.1177/1461444816661553

People.cn. (2016, May 25). Speech by Cheng Wei. Retrieved from https://bit.ly/2CxgtWW (in Chinese)

Raval, N., \& Dourish, P. (2016). Standing out from the crowd. Proceedings of the 19th ACM Conference on CSCW (pp. 97-107). New York, NY. Retrieved from https://doi.org/10.1145/2818048.2820026

Rosenblat, A., \& Stark, L. (2016). Algorithmic labor and information asymmetries. International Journal of Communication, 10, 3758-3784.

Srnicek, N. (2016). Platform capitalism. Cambridge, UK: Polity Press. 
Star, S. L., \& Ruhleder, K. (1996). Steps toward an ecology of infrastructure. Information Systems Research: ISR: A Journal of the Institute of Management Sciences., 7(1), 111-134.

State Information Center \& Internet Society of China. (2018). China's sharing economy development report 2018. Beijing. Retrieved from https://bit.ly/2QTlmmd (in Chinese)

Ticona, J., \& Mateescu, A. (2018). Trusted strangers: Carework platforms' cultural entrepreneurship in the on-demand economy. New Media \& Society, 20(11), 4384-4404. Retrieved from https://doi.org/10.1177/1461444818773727

Turow, J., \& Couldry, N. (2018). Media as data extraction. Journal of Communication, 68(2), 415-423.

Van Dijck, J., Poell, T., \& de Waal, M. (2018). The platform society. Oxford University Press.

Van Doron, N. (2017). Platform labor. Information, Communication \& Society, 20(6), 898-914. Retrieved from https://doi.org/10.1080/1369118X.2017.1294194

Wen, X. (2018, December 10). The real nature of sharing economy is a labor-intensive economy. The Paper. Retrieved from https://www.thepaper.cn/newsDetail_forward_2716522 (in Chinese)

Xiao, E. (2017, April 29). DiDi's quest for China's transportation data. Retrieved from https://bit.ly/2pNeSHM

Yangtze Evening Paper. (2017, November 15). Online and offline vehicles not match, DiDi fined by four cities. Retrieved from http://www.xinhuanet.com/201711/15/c_1121957526.htm (in Chinese)

Yue, Shaoxue. (2018, July 2). Rank of business licenses for close to a hundred ride-haling platforms and their nationwide distribution. Retrieved from http://m.evpartner.com/news/detail-37434.html (in Chinese)

Zhao, Y. (2007). After mobile phones, what? International Journal of Communication, $1(1), 92-120$.

Zittrain, J. (2009). The future of the Internet. New Haven, CT: Yale University Press.

Zuboff, S. (2015). Big other: Surveillance capitalism and the prospects of an information civilization. Rochester, NY: Social Science Research Network. Retrieved from https://papers.ssrn.com/abstract=2594754 